\title{
O jogo digital on-line e as funçōes cognitivas de atenção e memória em Matemática: um estudo em neurociências
}

\author{
Sindia Liliane Demartini da Silva*, Nilce Fatima Scheffer ${ }^{\star \star}$
}

\section{Resumo}

Este artigo tem por objetivo apresentar um produto educacional referente a uma pesquisa desenvolvida no Programa de Pós-Graduação Profissional em Educação da Universidade Federal da Fronteira Sul, campus Erechim. Trata-se dos jogos digitais on-line: Space Race e Batalha Matemática, que oferecem estratégias para o desenvolvimento das funções cognitivas humanas. Definimos o perfil dos estudantes nativos digitais e mostramos o jogo como perspectiva inovadora aos processos de ensinar e aprender. Apresentamos uma breve revisão de estudos relativos às funções cognitivas de atenção e memória associadas ao uso das tecnologias digitais de informação e comunicação na perspectiva da neurociência. Os resultados apontam que o estudante mantém a atenção sensorial/mental voltada à atividade quando está interagindo com o jogo, bem como faz o uso da memória de trabalho e de processos de evocação e consolidação de memória permanente. Consequentemente, estes e outros jogos digitais podem ser considerados importantes aliados à aprendizagem matemática.

Palavras-chave: Aprendizagem. Atenção. Jogos digitais. Matemática. Memória.

* Mestre em Educação pelo Programa de Pós-Graduação Profissional em Educação da Universidade Federal da Fronteira Sul, campus de Erechim. E-mail: sindialiliane@yahoo.com.br

* Mestre e Doutora em Educação Matemática pela Universidade Estadual Paulista, Rio Claro, SP. Professora da Universidade Federal da Fronteira Sul, no Programa de Pós-Graduação em Educação e no Programa de Mestrado Profissional em Matemática em Rede Nacional, no campus de Chapecó, e no Programa de Pós-Graduação Profissional em Educação, no campus de Erechim. E-mail: nilce.scheffer@uffs.edu.br 


\section{Introdução}

O perfil dos estudantes nativos digitais, ${ }^{1}$ bem como o modo como adquirem o conhecimento, vem sendo cada vez mais investigado nos últimos anos. Pesquisadores têm buscado respostas de convergência entre ensino, aprendizagem e tecnologias digitais, para garantir o sucesso na educação contemporânea.

$\mathrm{O}$ produto educacional apresentado neste artigo atende esta demanda, trata-se de parte dos resultados da dissertação de mestrado intitulada A interatividade dos jogos digitais na aprendizagem matemática: uma discussão em neurociência, desenvolvida no Programa de Pós-Graduação Profissional em Educação da Universidade Federal da Fronteira Sul, campus de Erechim, a qual traz uma investigação acerca da neurociência cognitiva, dos jogos digitais on-line e da aprendizagem matemática.

As pesquisas em neurociências têm contribuído para o conhecimento detalhado de como se caracteriza o cérebro e o seu funcionamento, o que pode colaborar no trabalho pedagógico, pois, ao conceber as funções cognitivas, será possível compreender mais detalhadamente as etapas da aprendizagem (SILVA; SCHEFFER, 2016, p. 8).

É no sentido de efetivar propostas que respeitem os fatores biológicos de desenvolvimento das funções cognitivas dos estudantes que se apresenta a abordagem dos aspectos de atenção e memória correlacionados à aprendizagem matemática e à aprendizagem baseada em jogos digitais. Essa proposta está de acordo com as necessidades e os estilos de aprendizagem da geração atual e das futuras gerações, por ser versátil, passível de ser adaptada a quase todas as disciplinas e considerada uma forma de aprender divertida e motivadora (PRENSKY, 2012, p. 23). Deste modo, os jogos digitais constituem-se em possibilidades educativas capazes de proporcionar um ambiente estimulador e desafiador, fazendo com que o estudante seja mais autônomo e independente em sua aprendizagem, o que o situa no seu espaço e tempo.

No que tange à educação matemática, a inovação tecnológica permitiu a exploração e o surgimento de outros cenários para o ensino e a aprendizagem da disciplina, tornando-se uma importante aliada (BORBA; SILVA; GADANIDIS, 2014, p. 17-18). Nesse sentido, as tecnologias digitais têm despertado a sensibilidade dos professores quanto à existência de diferentes representações que favorecem a análise dos procedimentos de resolução, conceitos e estratégias desenvolvidas pelos estudantes, sendo cada vez mais útil como recurso educativo (SCHEFFER, 2017, p. 37). 
De acordo com alguns pesquisadores, as tecnologias digitais vieram somar na disciplina de Matemática, enriqueceram muito os processos de ensinar e de aprender, pois uma demonstração que era estática, escrita no papel, passou a ganhar vida e movimento por intermédio de um software dinâmico, um aplicativo ou um jogo digital, por exemplo, tornando a aprendizagem mais expressiva, atraente e investigativa.

Este artigo apresenta uma abordagem de estudos relativos às funções cognitivas de atenção e memória correlacionadas ao jogo digital on-line de conteúdo matemático, trazendo alguns resultados de um produto de intervenção pedagógica que faz parte de uma dissertação desenvolvida em programa de pós-graduação.

Inicialmente, faz-se uma breve reflexão a respeito de atenção e memória na perspectiva da neurociência; na segunda parte, abordam-se os jogos digitais on-line de conteúdo matemático; na terceira parte, é apresentada a proposta prática relativa aos jogos, com a devida exploração, o que se constitui em proposta prática de intervenção para os professores aplicarem em suas aulas.

\section{As funções cognitivas atenção e memória}

A atenção e a memória são processos inter-relacionados, fundamentais no processamento de informações do cérebro e muito evidentes na aprendizagem matemática. Segundo Cosenza e Guerra (2011), embora sejam recentes as descobertas das relações entre a matemática e o cérebro, já se tem compreensão de como o cérebro lida com os números e a matemática básica. Desse modo, os autores argumentam que:

As habilidades matemáticas mais complexas ainda não foram suficientemente estudadas, e podem envolver outros sistemas cerebrais. Nosso conhecimento atual nos permite afirmar que a memória operacional e a atenção têm de ser envolvidas na resolução de problemas matemáticos e, portanto, os circuitos com elas relacionadas serão certamente mobilizados (COSENZA; GUERRA, 2011, p. 115).

Portanto, de acordo com os pesquisadores, a atenção e a memória são funções que auxiliam o cérebro humano a lidar com os números. Quando os números se apresentam no formato de jogos digitais, podem contribuir no desenvolvimento destas habilidades, segundo suas características de concentração e memorização.

Para as finalidades do estudo desenvolvido, a atenção e a memória foram tratadas como coadjuvantes na aprendizagem matemática, principalmente no caso 
do trabalho apresentado, assim, parte-se da definição e da caracterização destas funções para, posteriormente, concebê-las no cenário interativo.

\section{A atenção}

É comum ao discurso dos educadores a sentença "prestem atenção". Nos dias atuais, embora não definida como uma função neural, intuitivamente, sabe-se que é uma das condições que levam à aprendizagem. Inúmeras são as buscas dos educadores e pesquisadores quanto ao entendimento, às contribuições, ao significado e à compreensão do termo atenção nos processos de aprendizagem.

Prestar atenção é focalizar a consciência, concentrando os processos mentais em uma única tarefa principal e colocando as demais em segundo plano. É natural intuir que essa ação focalizadora só se torna possível porque conseguimos sensibilizar seletivamente um conjunto de neurônios de certas regiões cerebrais que executam a tarefa principal, inibindo as demais. Isso significa que a atenção tem dois aspectos principais: (1) a criação de um estado geral de sensibilização, conhecido atualmente como alerta, e (2) a focalização desse estado de sensibilização sobre certos processos mentais e neurobiológicos - a atenção propriamente dita (LENT, 2010, p. 631).

Logo, prestar atenção em algo consiste em direcionar-se para um único estímulo, de modo a focar pensamentos e comandos para uma determinada ação, o que torna o ser humano mais sensível e concentrado naquele instante.

Quando se refere à origem do estímulo, a atenção é classificada em: atenção sensorial e atenção mental. De acordo com Lent (2010) e Herculano-Houzel (2009), a atenção sensorial pode ser despertada pelas funções dos cinco sentidos: tato, olfato, paladar, audição e visão. Assim, o uso da visão é muito importante, pois, embora o campo alcançado no movimento dos globos oculares seja vasto, só prestamos atenção quando fixamos o olhar no objeto selecionado. Por exemplo, no momento em que você está prestando atenção nas palavras que está lendo, as demais palavras desta página, estão em segundo plano, mas também é possível que você esteja com o olhar focalizado nesta página, mas, na verdade, prestando atenção à letra de uma música que está tocando no seu fone de ouvido. Assim, quando a atenção coincide com a fixação do olhar, diz-se que é explícita ou aberta; quando o foco da atenção não coincide com o olhar, diz-se que é implícita ou oculta. Já a atenção mental ocorre quando há o foco da atenção estimulado no intelecto. Por exemplo, quando se utilizam processos e lembranças para resolver uma equação matemática, um algoritmo 
ou relações de representação. Dessa maneira, pode-se dizer que a atenção sensorial e a atenção mental atuam em conjunto, ao considerar que o foco se alterna entre uma e outra na maioria das atividades humanas.

Cosenza e Guerra (2011) classificam a atenção em terminologias diferentes, mas com definições semelhantes, chamam de atenção reflexa aquela proveniente de estímulos periféricos e de atenção voluntária aquela regulada por aspectos centrais do processamento cerebral. Por exemplo,

[...] podemos lembrar como exemplo de atenção reflexa o que acontece quando um som intenso ocorre repentinamente, como o sinal que anuncia a hora do recreio. Em relação à atenção voluntária, podemos imaginar a procura de um objeto perdido, em que somos capazes de encontrá-lo mais facilmente - na confusão de uma gaveta, por exemplo - quando mantemos a atenção concentrada (COSENZA; GUERRA, 2011, p. 44).

Esta posição dos autores vem confirmar que a atenção não é um fenômeno particular, existem diferentes mecanismos que a regulam no sistema funcional de vigilância, e nós, educadores, precisamos considerar isso no momento em que estamos buscando, juntamente com nossos estudantes, construir significados matemáticos.

Nesta ótica, Herculano-Houzel (2009) destaca que a grande porta da aprendizagem é a atenção, pois ela funciona como um filtro do cérebro na seleção da informação que será processada de maneira especial, ou seja, conduzida para uma memória de trabalho, isto é, a memória de curta duração, que permite ao cérebro trabalhar com várias informações ao mesmo tempo. O cérebro não dá conta de processar todas as informações que chegam até ele, portanto é por meio da atenção que selecionamos a informação mais relevante e desconsideramos outras desnecessárias.

Consequentemente, é comum, no dia a dia, uma infinidade de informações concorrentes, e nosso foco está continuamente lutando contra as distrações. Para crianças e adolescentes, isso é ainda mais perturbador, pelo fato de que estão em fase de consolidação de seus aspectos formativos. Assim, o nível de estímulos que nos rodeiam é alto, a capacidade de manter o foco em um alvo e ignorar todo o resto é uma funcionalidade do cérebro, localizada na região pré-frontal, encarregada de aumentar a força dos sinais direcionados ao que queremos nos concentrar e diminuir as forças dos sinais do que escolhemos ignorar, a esse processo denomina-se atenção seletiva (COSENZA; GUERRA, 2011, p. 22).

A escola, assim como os demais ambientes de socialização, está cheia de informações, tensões, competições e tentações da vida moderna, que capturam a aten- 
ção a todo o momento. Nesse ambiente, o professor deve constantemente "chamar para a aprendizagem", direcionando a atenção seletiva dos estudantes, e isto será bem-sucedido quando forem oferecidos estímulos significantes para estudar a lição, dado que:

[...] o cérebro tem uma motivação intrínseca para aprender, mas só está disposto a fazê-lo para aquilo que reconheça como significante. Portanto a maneira primordial de capturar a atenção é apresentar o conteúdo a ser estudado de maneira que os alunos o reconheçam como importante (COSENZA; GUERRA, 2011, p. 48).

Para Cosenza e Guerra (2011), é provável que seja considerado significante e, consequentemente, alvo da atenção aquilo que faça sentido no contexto em que vivem os estudantes e tenha correlação com suas experiências e expectativas. É favorável, nesse sentido, oferecer um ambiente escolar estimulante, ministrando aulas com métodos e recursos diversificados, pois a manutenção da atenção por um período prolongado exige a ativação de circuitos neurais mais específicos, e, se não houver uma flexibilização de técnicas e recursos, a tendência é que o foco da atenção seja desviado para outros estímulos, dificultando a efetiva aprendizagem (COSENZA; GUERRA, 2011, p. 48).

Vale ressaltar que a atenção assume sua importância e a utilização de tecnologias digitais se constitui em um momento real de aprendizagem dinâmica, com os jogos digitais sendo aliados na compreensão matemática.

\section{A memória}

Neste momento, ao ler este texto, você está utilizando muito da sua memória: seu aprendizado relacionado ao reconhecimento das representações das letras para a leitura das palavras e frases, a interpretação dos grupos de palavras de acordo com conhecimentos gramaticais, a associação destas novas informações com as já registradas, o armazenamento dos significados contidos nos parágrafos anteriores para dar sentido aos posteriores, ou seja, se isso tudo não estivesse arquivado previamente em sua memória, seria impossível realizar esta tarefa. Memória é, segundo Lent (2010), a capacidade humana de armazenar informações que possam ser recuperadas e utilizadas posteriormente. 
Nem todas as informações acondicionadas diariamente em nosso cérebro constituirão memórias. Izquierdo (1989) explica que, para entender a formação de memórias a partir de experiências, é preciso considerar quatro aspectos fundamentais:

1) Recebemos informações constantemente por intermédio de nossos sentidos, mas não memorizamos todas. Há um processo de seleção prévio à formação de memórias que determina quais informações serão armazenadas e quais não.

2) As memórias não são gravadas na sua forma definitiva, existe um processo de consolidação depois da aquisição.

3) As memórias são também muito mais sensíveis à incorporação de informação adicional nos primeiros minutos ou horas após a aquisição.

4) As memórias consolidam-se na formação de registros (files) de caráter mais complexo, ou seja, não como itens isolados.

Esses fatores determinam a formação ou não de uma memória após uma experiência vivenciada, bem como sua resistência à extinção, à interferência e ao esquecimento.

Para Lent (2010), a informação filtrada pela atenção, advinda de forma externa através dos sentidos ou interna, quando surgem dos pensamentos e emoções, é conduzida ao Sistema Nervoso, e a primeira etapa dos sistemas de memória é a aquisição; seguindo para a retenção temporária, que é variável, ou seja, que pode durar anos ou apenas alguns segundos. Nessas condições, de acordo com o autor, a retenção temporária pode ser transformada em retenção duradoura pelo processo de consolidação da memória e, em ambos os casos, entretanto, pode haver a evocação ou o esquecimento das informações memorizadas.

Nessa perspectiva, de forma mais clássica, a mente humana é tratada considerando dois sistemas de memória interconectados, com características e funções diferentes, a memória de trabalho e a memória permanente. Conforme Pozo (2002), a memória de trabalho, de caráter transitório, funciona como um gerenciador de informações e recursos cognitivos, já a memória permanente constitui o banco de conhecimentos armazenados, que podem ser recuperados para realizar determinada tarefa.

Assim, a memória de trabalho é usada para entender a realidade que nos cerca, resiste o tempo suficiente para que possa formar a memória remota, que durará dias, anos ou décadas. Por exemplo, a memória da infância é remota, a lembrança do que aconteceu há alguns dias é memória de longa duração, as lembranças recentes do que estavas fazendo algumas horas antes de começar a ler este texto é memória de 
curta duração, e a memória das últimas palavras desta frase é memória de trabalho, que, por sinal, já foi perdida, durou apenas o tempo suficiente para entender a sequência da leitura (IZQUIERDO, 2010, p. 25-26).

Para Izquierdo (2010), a memória de trabalho não forma lembranças duradouras pelo simples motivo de que não seria possível ter uma sequência de informação coordenada, seja nesta leitura ou em qualquer outra atividade, se não deixássemos para trás imediatamente algumas delas.

Esse processo, fisiologicamente, depende da atividade elétrica de neurônios do córtex pré-frontal, localizado na frente da área motora, que são ativados em resposta às experiências de cada momento, de modo que, ao cessar a atividade, a memória de trabalho também cessa. É um mecanismo muito rápido, mas com função precisa, pois a informação processada pelo córtex pré-frontal se comunica com outras regiões do cérebro e faz o intercâmbio para o armazenamento de possíveis memórias de maior duração (IZQUIERDO, 2010, p. 27).

Izquierdo (2001) classifica as memórias seguindo duas vias: de acordo com o conteúdo e de acordo com o tempo que duram. Dessa forma, de acordo com o conteúdo descrito por este autor, as memórias são divididas em dois grupos, as declarativas e as procedurais. As memórias declarativas são governadas fundamentalmente pelo hipocampo, e suas conexões têm a função de registrar fatos, eventos ou conhecimentos dos quais podemos declarar que existem e relatar como adquirimos, como lembranças da comida da nossa vó, da aula de matemática, da música de formatura. São mais suscetíveis à modulação pelas emoções, pela ansiedade e pelo estado de ânimo. As memórias procedurais, mediadas pelo núcleo caudato e por suas conexões e também pelo cerebelo, estão relacionadas às habilidades motoras ou sensoriais, comumente chamadas de "hábitos", dos quais não precisamos declarar que possuímos, apenas demonstramos, como andar de bicicleta, nadar, ler, cantar, etc.

Para Lent (2010), estes grupos podem aparecer denominados como memórias explícitas, aquelas adquiridas com plena intervenção da consciência, e como memórias implícitas, aquelas adquiridas sem a percepção do processo.

Com exceção da memória de trabalho, que é on-line pela sua instantaneidade, as memórias são classificadas, por Izquierdo (2001), com relação ao tempo que duram, como memória de curta duração, memória de longa duração e memória remota. As memórias de longa duração são aquelas que permanecem por mais de seis horas, tempo que demora o processo de sua consolidação celular, dois ou três 
dias, semanas, meses ou até anos. As memórias de curta duração são aquelas que permanecem entre uma e seis horas, justamente o tempo necessário para a consolidação das memórias de longa duração. As memórias remotas são aquelas que duram muitos meses ou anos.

Nesse contexto, é preciso deixar claro que as memórias de curta e de longa duração envolvem processos independentes, porém paralelos, e que o hipocampo é a principal estrutura do Sistema Nervoso envolvida nas memórias, mas não é a única região cerebral mnemônica.

A nossa individualidade é fruto das nossas memórias, portanto:

[....] não podemos fazer aquilo que não sabemos, nem comunicar nada que desconheçamos, isto é, nada que não esteja na nossa memória [...]. O acervo de nossas memórias faz com que cada um de nós seja o que é: um indivíduo, um ser para o qual não existe outro idêntico (IZQUIERDO, 2010, p. 11).

Analogamente, temos nosso arquivo pessoal de memória sempre em formação, vamos editando nosso conteúdo com aquilo que lembramos, mas também com o que não queremos lembrar. Assim, a memória é um sistema organizacional tão bem articulado que a extinção é fundamental, alivia-nos de conhecimentos inúteis ou de aprendizagens passadas que foram sendo modificadas ao longo do tempo, com novos sentidos (POZO, 2002; IZQUIERDO, 2010, p. 40). Do mesmo modo, muitas das nossas memórias são perdidas ao longo dos anos, pela morte natural dos neurônios ou pela falta de uso das sinapses que as continham, causando então o esquecimento.

Considerando o exposto, pode-se dizer que a memória sadia não consiste em apenas reter aquilo que é significativo, mas também em abrir mão daquilo que é desnecessário para ceder espaço a novas informações, e a melhor forma de conservá-la é pela prática.

\section{Jogos digitais on-line de conteúdo matemático}

No contexto da educação matemática, é importante destacar o mérito do jogo como recurso didático, com o advento das tecnologias digitais, em especial dos avanços de hardware e software, que permitiram o surgimento de jogos digitais, houve uma rápida e eficiente virtualização dos jogos tradicionais.

Foi na década de 1990 que os jogos digitais começaram a ser inseridos no contexto escolar. Em virtude disto, os jogos tradicionais usados no ensino da Matemática 
foram sendo enriquecidos pelas mídias digitais, ao mesmo tempo em que estudos a este respeito vieram à tona, para comprovar que o uso de tal recurso proporciona aos jogadores a aquisição de habilidades que são de fundamental importância para a aprendizagem da disciplina (SANTOS; SILVA JUNIOR, 2014, p. 2-3).

Com experiências inovadoras, associando tecnologia à aprendizagem, é que, para Prensky (2012), acontece a verdadeira revolução da aprendizagem do século XXI, em que finalmente a enorme barreira que separava a aprendizagem da diversão e o trabalho do jogo se dissipa.

Assim, a utilização de jogos computadorizados na educação proporciona ao aluno motivação, desenvolvendo também hábitos de persistência no desenvolvimento de desafios e tarefas. Os jogos, sob a ótica de crianças e adolescentes, constituem a maneira mais divertida de aprender. Além disso, eles proporcionam a melhora da flexibilidade cognitiva, pois funcionam como uma ginástica mental, aumentando a rede de conexões neurais e alterando o fluxo sanguíneo no cérebro, quando em estado de concentração (TAROUCO et al., 2004, p. 3).

Dentre esses jogos computadorizados, os jogos digitais desempenham positiva influência em habilidades cognitivas referentes à Matemática, porque os desafios exigem capacidades inerentes à disciplina, como memória, raciocínio lógico, cálculo mental, resolução de problemas, agilidade, atenção, entre outras. A utilização desse recurso modifica a dinâmica do ensino e as estratégias que o professor pode utilizar para motivar e facilitar a aprendizagem.

Há aspectos a serem observados com cautela nos jogos on-line, porém os aspectos positivos são mais relevantes. Os jogos digitais são considerados, hoje, como um instrumento adicional aos processos de ensino e aprendizagem, pois ajudam a desenvolver conhecimentos e habilidades para um público que está habituado com as tecnologias. Por essa razão, as ações do professor são preponderantes, e é a escolha do jogo, do conteúdo e do momento oportuno de uso do recurso digital interativo para as aulas o que garantirá o êxito, de modo que os jogos digitais se tornem importantes aliados no processo.

A tendência é que as tecnologias digitais estejam cada vez mais presentes nas práticas de sala de aula; nesse contexto, entende-se que os jogos digitais podem ser elementos importantes para enriquecê-las, oferecendo desafios para o ato de aprender.

A seguir, apresentam-se dois jogos digitais on-line, disponíveis para acesso imediato em uma página da internet em tempo real, que envolvem operações ma- 
temáticas e desenvolvem as funções cognitivas de atenção e memória dos estudantes. Tratam-se dos jogos Space Race, descrito no Quadro 1, e Batalha Matemática, descrito no Quadro 2.

\section{Quadro 1 - Jogo Space Race (Corrida Espacial)}

Descrição: o jogo exibe quatro naves espaciais em ponto de partida para uma corrida intergaláctica. O jogador deve escolher uma das naves, com possibilidade de personalizá-la com nome e cor de sua preferência. Dada a largada, as naves movimentam-se e o jogador deve resolver a operação que sua nave contém e clicar na seta que indica a resposta certa o mais rápido possível para vencer a corrida. O jogo registra a posição das naves e o número de voltas simultaneamente com a ação do jogador. Ao final, é possível verificar a classificação final da corrida e os cálculos que não foram respondidos corretamente aparecem com as respostas certas.

Interface:

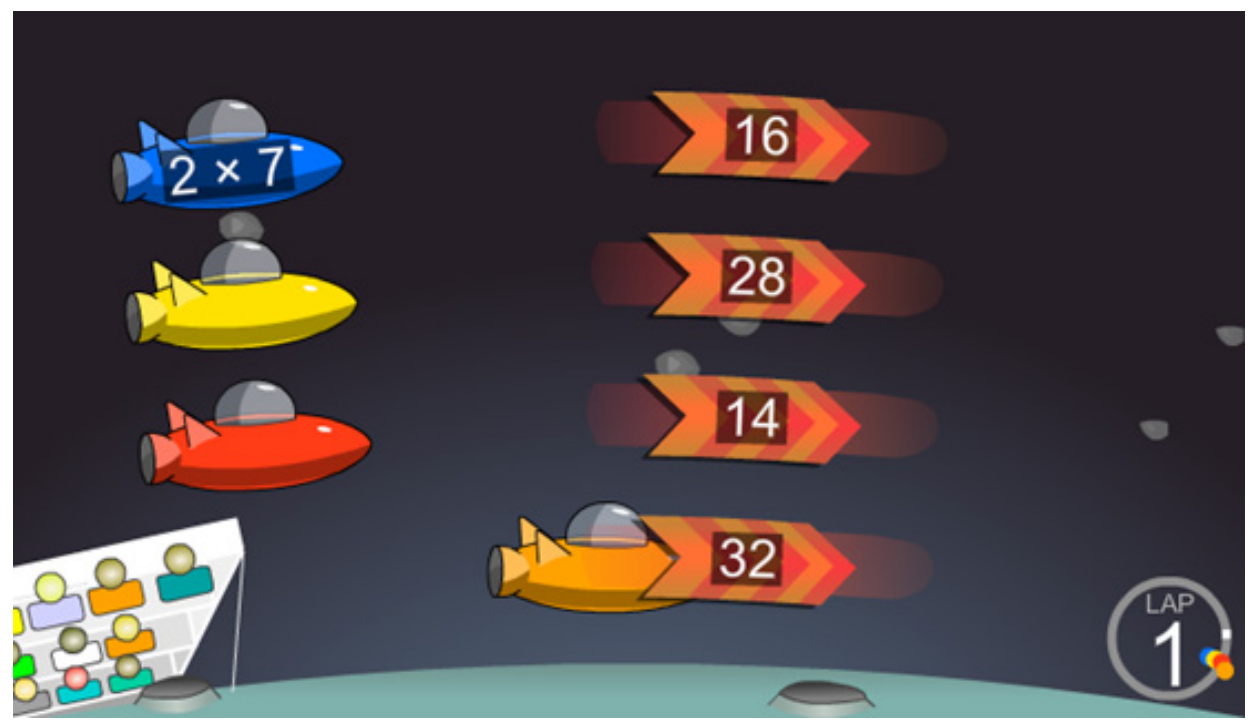

Fonte: http://poki.com.br/g/space-race. Acesso em: 12 jan. 2017.

Estrutura: este jogo pode ser executado com um único jogador e o computador ou por até quatro participantes.

Objetivo: resolver situações envolvendo a multiplicação de números naturais para vencer a corrida no espaço sideral.

Conceitos matemáticos: multiplicação/tabuada.

Habilidades: atenção, concentração, memória e raciocínio lógico.

Indicação: para estudantes do ensino fundamental, como estratégia de memorização da tabuada.

Como jogar:

$1^{\circ}$ passo: clique em play (jogar);

$2^{\circ}$ passo: clique em continue (continuar);

$3^{\circ}$ passo: escreva seu nome ou use um aleatório no quadro e clique em create (criar), clique novamente em create game (criar um jogo), e em seguida clique em start race (iniciar corrida);

$4^{\circ}$ passo: resolva a operação que sua nave contém e clique na seta que contém a reposta certa o mais rápido possível para vencer a corrida.

Na seta à direita do teclado, é possível acelerar o movimento da nave no intervalo entre um cálculo e outro.

Fonte: autoras, 2017. 


\section{Quadro 2 - Jogo Batalha Matemática}

Descrição: o jogo simula a tentativa de invasões inimigas a uma fazenda; para vencer a batalha, o jogador deve resolver operações matemáticas mentalmente, a tempo de eliminar o ataque de cada um dos inimigos que se aproximam. São eles: a abelha, que traz cálculo de adição; o fogo, que traz cálculo de subtração; o fantasma, que traz cálculo de multiplicação; a nave alienígena, que traz cálculo de divisão; a água, que traz expressão numérica de adição; e a mosca, que traz expressão numérica de subtração. Este jogo possui doze níveis, os quais o jogador só pode avançar em ordem; aparecem como dia 1, dia 2, e assim sucessivamente, registrando o recorde de cada dia (nível) e também o recorde total, permitindo o desafio de superá-lo a cada nova batalha.

\section{Interface:}

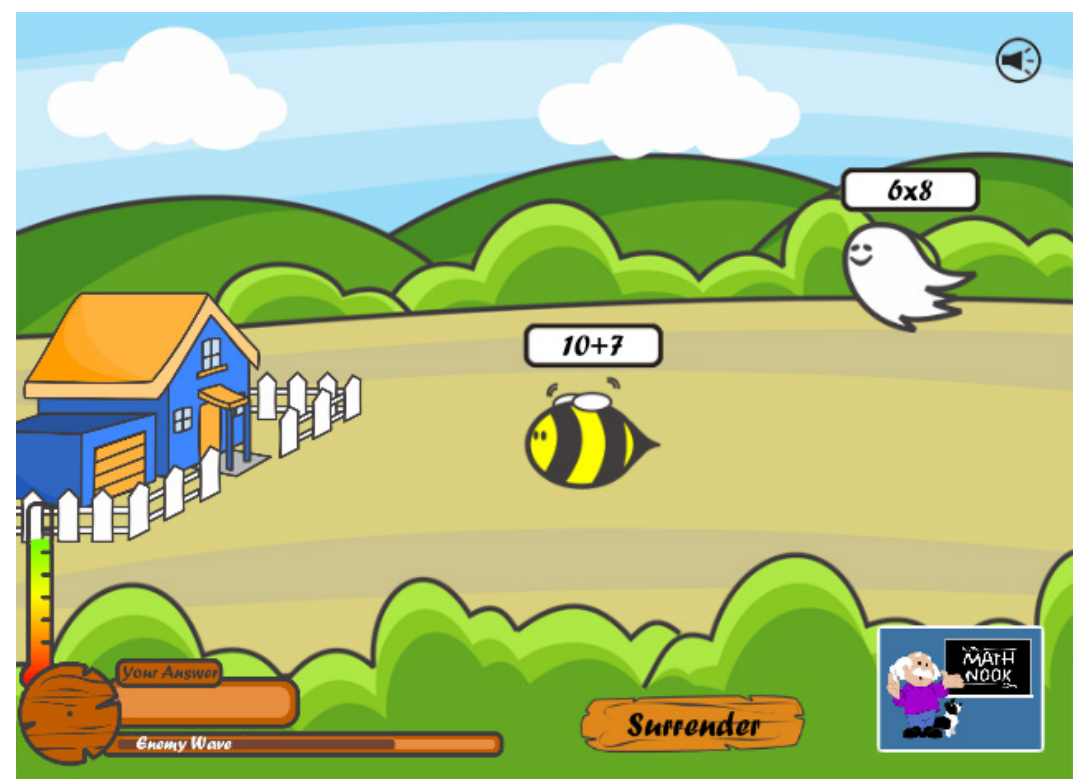

Fonte: http://www.atividadesdematematica.com/jogos-educativos-infantis/batalha-matematica. Acesso em: 12 jan. 2017.

Estrutura: este jogo é uma disputa entre o jogador e o computador, podendo ser lançado como desafio entre mais jogadores.

Objetivo: resolver situações envolvendo cálculo mental e operações de adição, subtração, multiplicação e divisão de números naturais, bem como expressões numéricas, para proteger sua fazenda do ataque de inimigos.

Conceitos matemáticos: adição, subtração, multiplicação e divisão de números naturais, expressões numéricas e cálculo mental.

Habilidades: atenção, concentração, memória, cálculo mental e raciocínio lógico.

Indicação: para estudantes do ensino fundamental em fase de desenvolvimento de cálculo mental com as quatro operações básicas dos números naturais.

\section{Como jogar:}

$1^{\circ}$ passo: clique em play (jogar);

$2^{\circ}$ passo: selecione o nível;

$3^{\circ}$ passo: ao avistar o invasor, digite a resposta do cálculo nele expresso e acione enter, para eliminá-lo, e assim sucessivamente, antes que o tempo acabe.

Quando o tempo acaba, aparecerá a expressão "You win!" (Você ganhou!) e a pontuação, caso tenha superado o recorde daquele nível; caso contrário, aparecerá a expressão "You lose!" (Você perdeu!).

Fonte: autoras, 2017. 
No jogo Space Race (Quadro 1), o estudante precisa estar atento e concentrado para dar respostas rápidas às multiplicações e direcionar a sua nave no espaço correspondente. A tabuada memorizada é importante, pois, se o jogador precisar utilizar as técnicas de soma consecutiva, ou contagem de agrupamentos, perderá tempo em direcionar a nave para a resposta correta. Por exemplo, a resposta memorizada de $4 \times 3=12$ será muito mais rápida do que pensar em $4 \times 1=4$, para $4 \times 2$, acrescento 4 e obtenho 8 , para $4 \times 3$, acrescento 4 novamente e obtenho 12 , ou seja, $4 \ldots 8 \ldots 12$.

O jogo Batalha Matemática (Quadro 2) tem como pré-requisitos atenção e memória, as expressões de cálculo aparecem em representação simples, mas a concentração ao observar qual inimigo está mais próximo, a rapidez na tomada de decisão e a memorização dos algoritmos de adição, subtração, multiplicação e divisão é que permitirão ao estudante responder corretamente, avançar de nível ou vencer o jogo com mais facilidade.

Esses jogos digitais favorecem o aperfeiçoamento das habilidades de cálculo mental elaboradas a partir de uma atividade divertida, o que permite ganhos também no desenvolvimento das funções cognitivas do estudante.

Pela permanente plasticidade do cérebro, Cosenza e Guerra (2011, p. 36) explicam que "[...] o treino e a aprendizagem podem levar à criação de novas sinapses e à facilitação do fluxo de informações dentro de um circuito nervoso", ou seja, o treinamento constante de uma determinada atividade favorece as ligações sinápticas entre as conexões estimuladas, o que faz com que tal atividade seja realizada de forma cada vez mais eficiente.

Para Prensky (2012), interagir periodicamente com jogos digitais torna áreas específicas do cérebro mais desenvolvidas, pois é resultado de experiências repetidas.

$\mathrm{Na}$ interação dos estudantes com estes jogos, foi possível constatar aspectos que demonstram o estado atencional provocado tanto pelos estímulos sensoriais quanto pela atenção mental. Os sinais emitidos pelo corpo por meio de expressões faciais, gestos, movimento ou falta de movimento são indicativos do estado de atenção do indivíduo. Por exemplo, fixar o olhar em direção à tela do computador, como as estudantes E5 e E6 (Figura 1), é uma característica de alguém que está direcionando seu foco atencional para um único estímulo sensorial, deixando de lado outros. Cosenza e Guerra (2011, p. 42) ilustram que a atenção é comparada a uma lanterna na janela de nossa percepção, focalizando um dos nossos sentidos ou o nosso pensamento. 
Figura 1 - E5 e E6 em atividade com o jogo Batalha Matemática

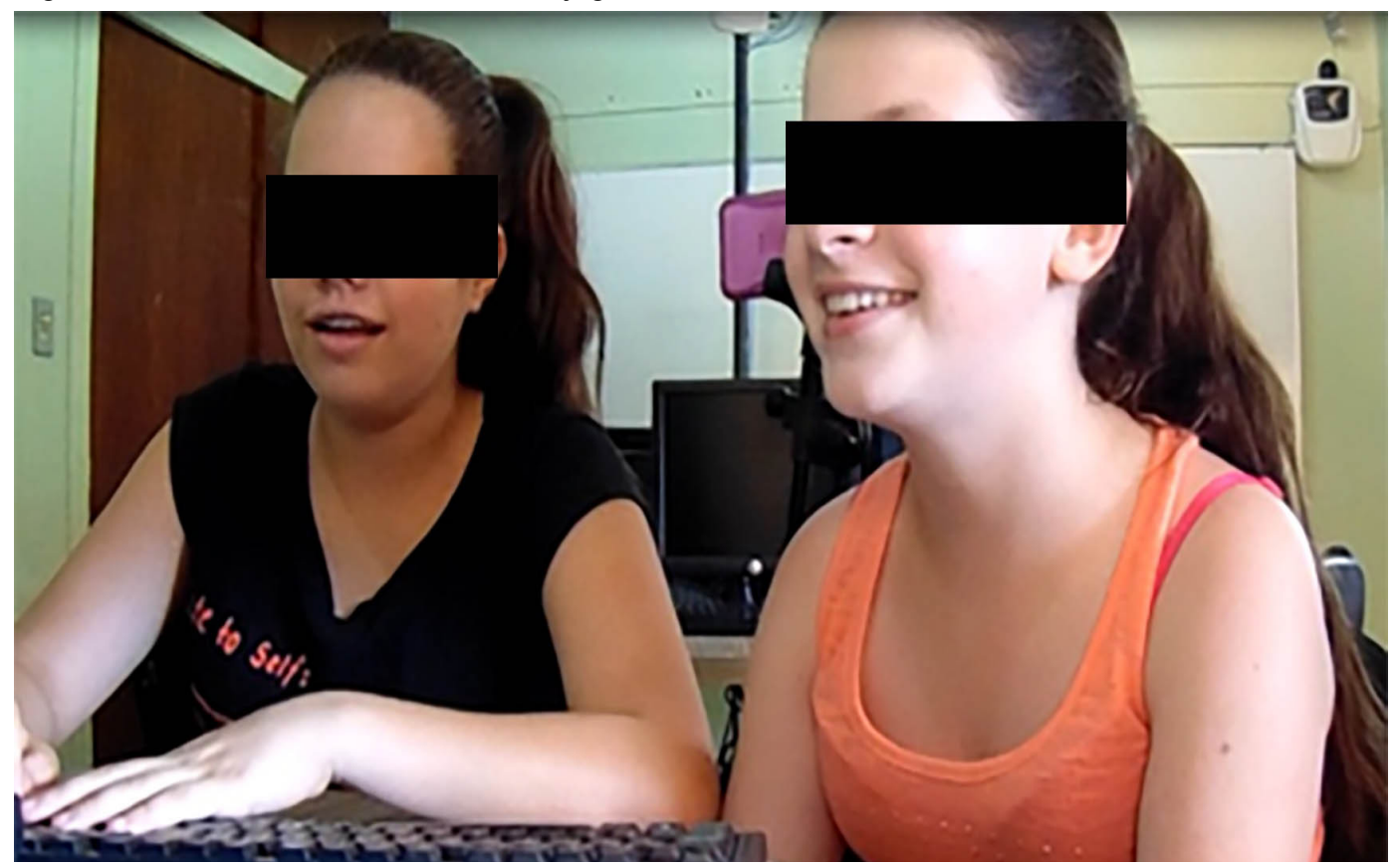

Fonte: autoras, 2017.

Em diversos momentos, os estudantes participantes fizeram movimentos de sentar em posição ereta, aproximar a cabeça e fixar os olhos em direção à tela do computador, quando pareciam querer se concentrar mais. Outro aspecto comportamental evidente da atenção é o silêncio. Durante as oficinas, mesmo com a solicitação da pesquisadora para que falassem o que estavam fazendo durante o jogo, diversas vezes, quem estava jogando permanecia calado ou apenas resmungava, principalmente quando o jogo estava em um nível que exigia maior rapidez de resposta.

O foco de atenção dos estudantes, por vezes, foi acometido aos estímulos emocionais, este aspecto foi observado em E4 na interação com o jogo Batalha Matemática (Figura 2), no momento em que está realizando cálculos com mais parcelas, já no 4⿳⺈ nível do jogo, o estudante se irrita com o comentário e o riso do colega mediante o erro da soma $5+4$, perdendo o foco, reclama não se lembrar da multiplicação $6 \times 5$ e, como pode ser visto no diálogo, se atrasa para dar as respostas e os cálculos se acumulam: 
E3: Cinco com quatro dá quanto, dá oito? (risos)

E4: Ah cara! Não incomoda!

E4: Nã! (ergue o braço). Eu me esqueci.

E4: Nossa, eu "minei” de número!

Nesses casos, o efeito negativo no desempenho da atividade está relacionado à distração emocional. Para Goleman (2014), as emoções guiam o foco, quando nos sentimos dominados por emoções, fixamos nossa atenção àquilo que é mais perturbador, isso faz com que nos esqueçamos do resto. Portanto, quando não há atenção, ou seja, quando se apresenta a distração, seja ela sensorial ou emocional, a mente divaga. Por consequência, se não há foco naquilo que está a ser aprendido, o cérebro não situa aquela informação nas redes neurais (GOLEMAN, 2014, p. 22).

A partir dos dados expostos, pode-se constatar que a atividade realizada com os estudantes reafirma os conceitos de que o ambiente externo influencia na condição atencional, bem como que as emoções da relação do estudante com a mídia e do estudante com seus pares direcionam o foco, que, por sua vez, determina o bom ou o mau desempenho das atividades desenvolvidas no jogo que está sendo proposto.

Os jogos digitais, junto com os videogames, são considerados, por Prensky (2012, p. 155), como os passatempos que mais prendem a atenção de seus usuários na história da humanidade. O autor justifica essa prerrogativa ao destacar que:

Jogos são uma forma de diversão, o que nos proporciona prazer e satisfação. Jogos são uma forma de brincar, o que faz nosso envolvimento ser intenso e fervoroso. Jogos têm regras, o que nos dá estruturas. Jogos têm metas, o que nos dá motivação. Jogos são interativos, o que nos faz agir. Jogos tem resultados e feedback, o que nos faz aprender. Jogos são adaptáveis, o que nos faz seguir um fluxo. Jogos têm vitórias, o que gratifica nosso ego. Jogos têm conflitos/ competições/desafios/oposições, o que nos dá adrenalina. Jogos envolvem a solução de problemas, o que estimula nossa criatividade. Jogos têm interação, o que nos leva a grupos sociais. Jogos têm enredo e representações, o que nos proporciona emoção (PRENSKY, 2012, p. 156).

Esses elementos foram alvo de observação nas oficinas de interação dos estudantes com os jogos apresentados, alguns serão detalhados na sequência do texto, destacados em itálico.

No jogo Batalha Matemática, a simulação é de uma batalha, mas com inimigos singelos, que vão surgindo conforme o nível avançado no jogo: abelha, fogo, água, extraterrestre, mosca, fantasma (Figura 2). O jogador precisa fazer os cálculos para eliminar cada inimigo, antes que chegue à sua fazenda. 
Figura 2 - Etapa do jogo Batalha Matemática

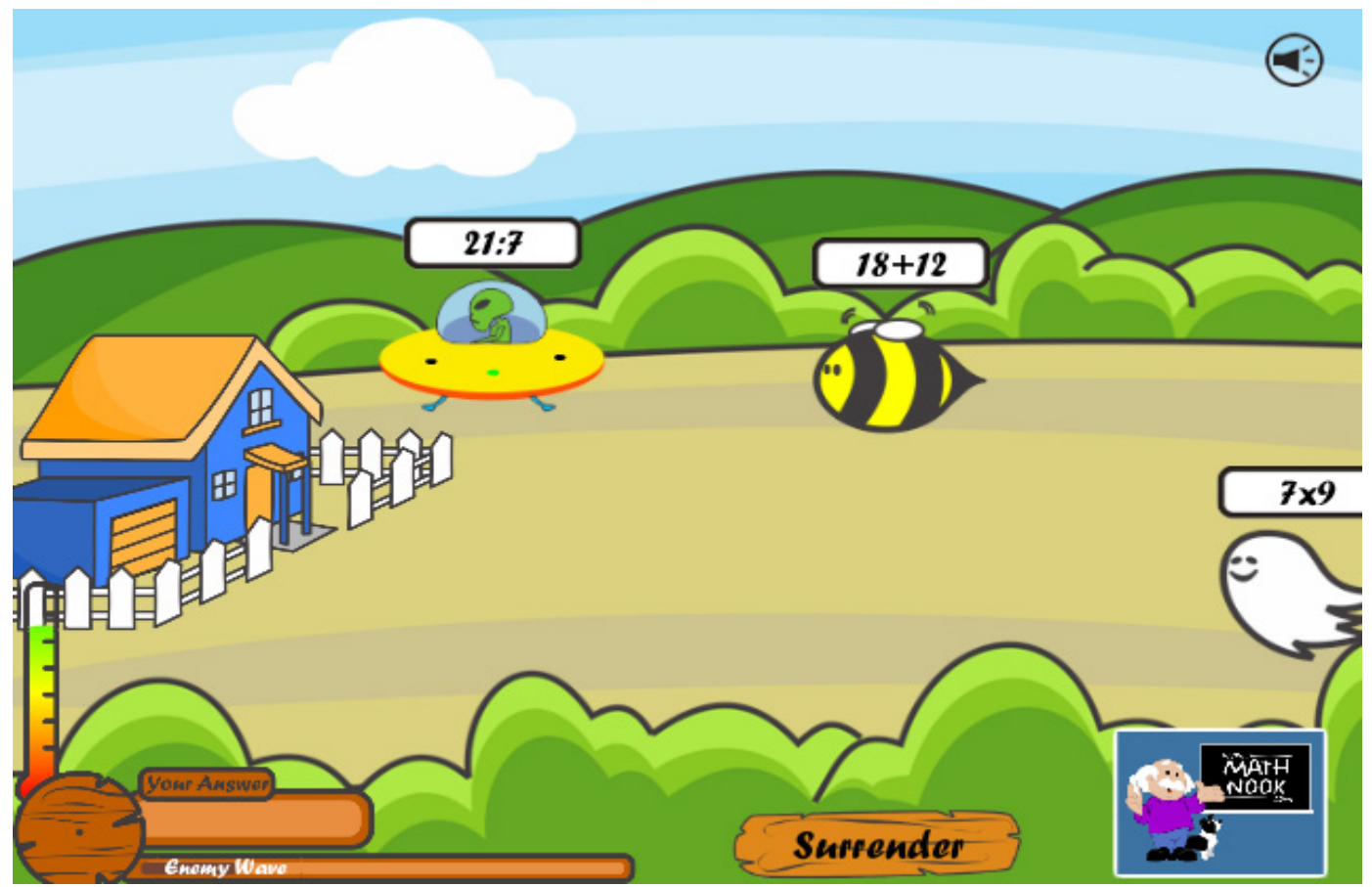

Fonte: autoras, 2017.

Batalha Matemática é um jogo que registra o recorde de pontuação de cada nível e também o recorde geral. A Figura 3 mostra o registro de um jogador que já atingiu o $11^{\circ}$ nível do jogo, tem um recorde total de 22.040 pontos; apontado pela flecha, há o recorde do $4^{\circ}$ nível, que é de 2.030 pontos, o que permite o desafio de superá-los a qualquer tempo, tanto individualmente quanto, no caso deste estudo, entre dois jogadores. 
Figura 3 - Níveis e recordes do jogo Batalha Matemática

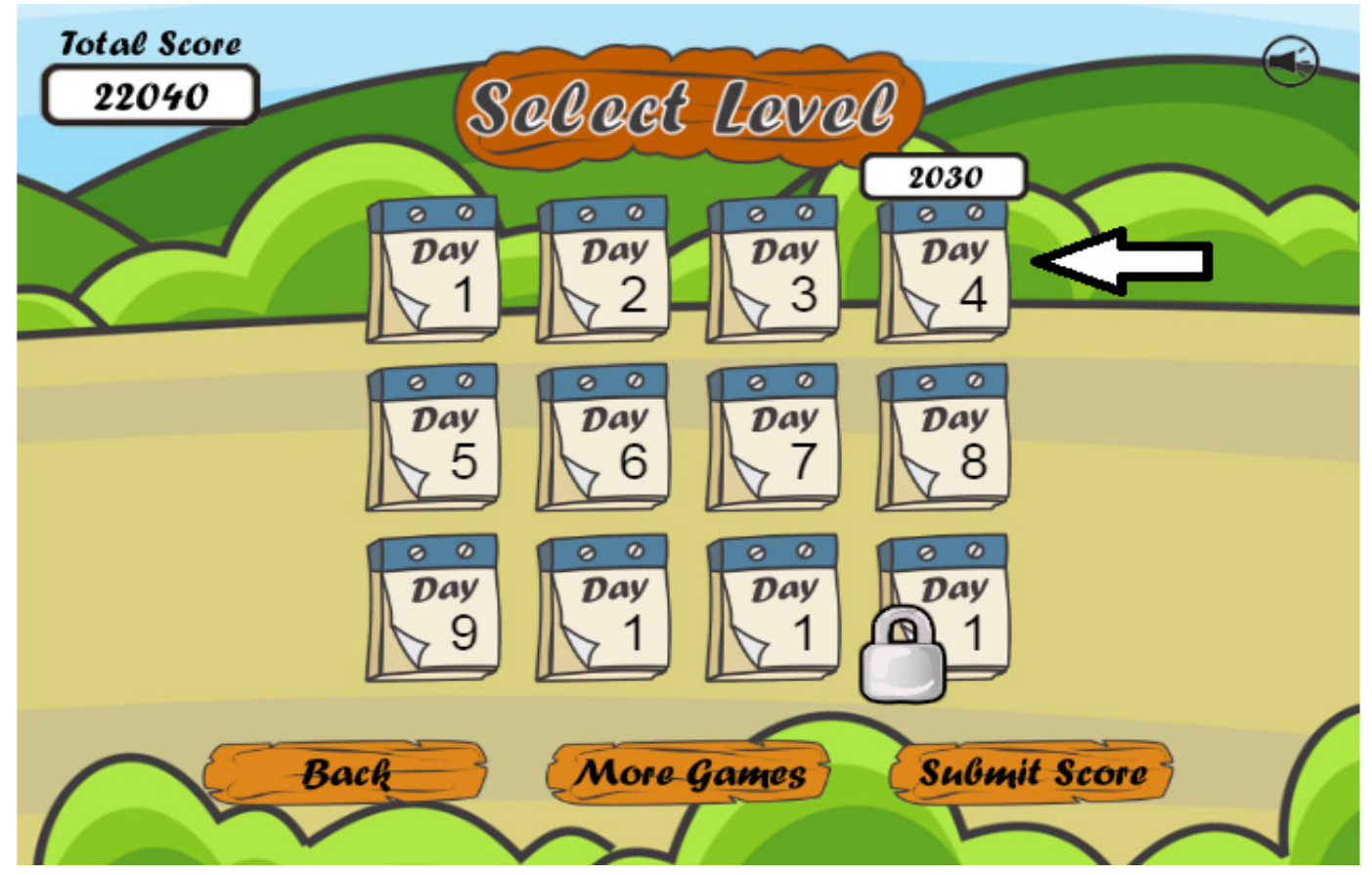

Fonte: autoras, 2017.

Constatou-se, pelas manifestações dos estudantes, que elementos como imagens, animações, sons e feedback são imprescindíveis para chamar a atenção e manter $o$ foco na atividade.

Os estudantes observavam todos os detalhes dos jogos, de modo que manifestavam atenção sensorial, motivada por visão e audição, e também atenção mental, nos momentos em que estavam calculando. Isso leva a considerar que o enredo e as representações que os jogos digitais apresentam são fatores de grande relevância quando o objetivo é prender a atenção dos jogadores.

O jogo Space Race traz um cenário que desperta a imaginação, é uma corrida espacial que pode envolver a disputa de até quatro jogadores, que resolvem cálculos para vencer a corrida, como demonstra a Figura 4. 
Figura 4 - Etapa do jogo Space Race

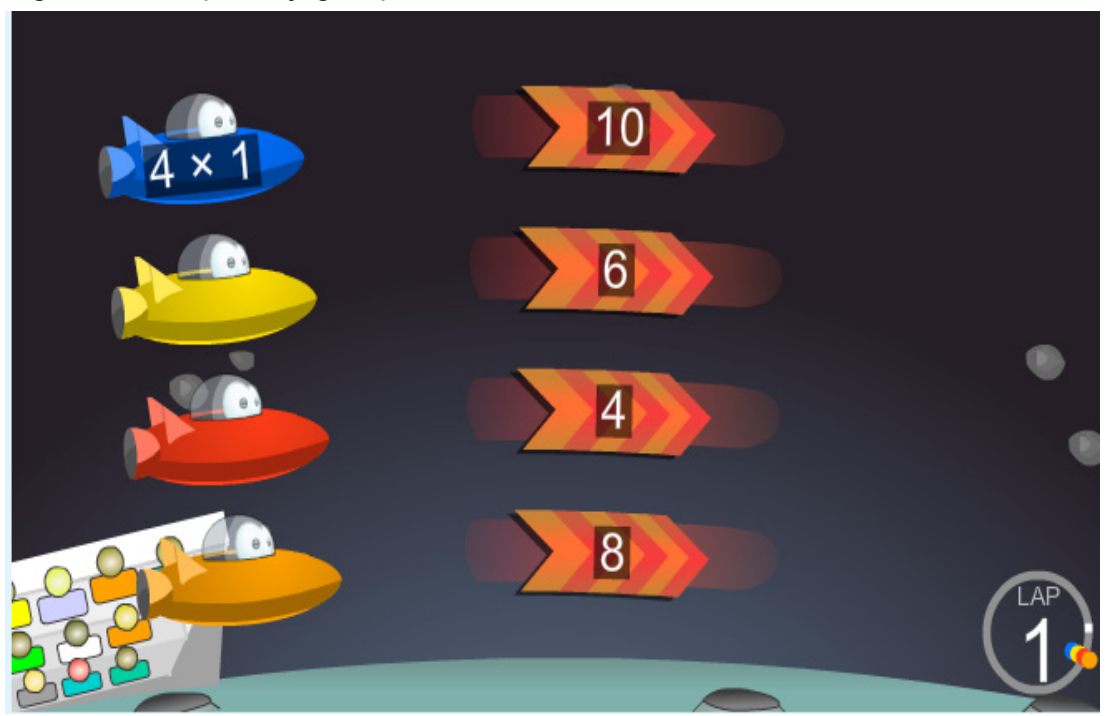

Fonte: autoras, 2017.

No final, o jogo oferece o feedback com a classificação das naves e a lista de cálculos que não foram resolvidos corretamente pelo jogador com resposta certa, como consta na Figura 5, finalização do jogo de E2.

Figura 5 - Classificação de E2 no jogo Space Race

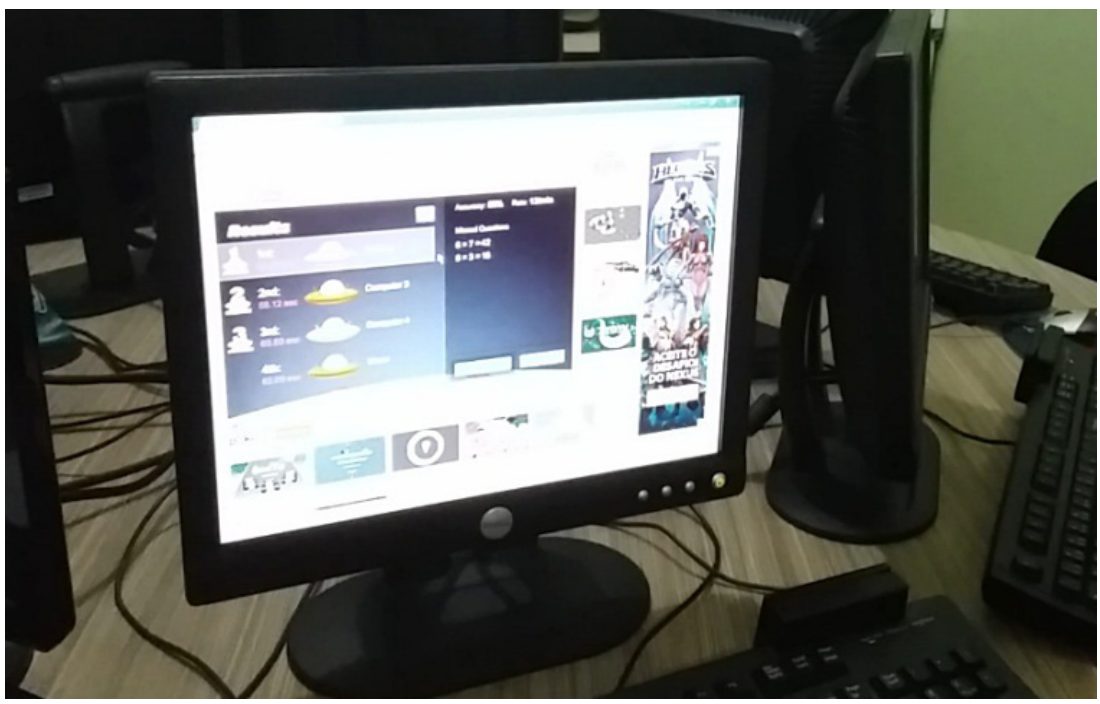

Fonte: autoras, 2017. 
E2: Eeeeeh! (comemora e sorri)

E1: Chegou em primeiro?

E2: Primeiro. Errei seis vezes sete e seis vezes três.

P: Como foi esse jogo?

E2: Foi bom!

E1: Muito bom!

E2: Legal!

E1: O melhor de todos profe!

P: É? Por que melhor?

E2: Porque é legal ter que fazer rápido as contas daí tem que acelerar, é legal.

Pela fala dos estudantes, nota-se que o formato de corrida do jogo desperta ainda mais a emoção da disputa, as multiplicações durante o percurso são de números menores, a maioria delas memorizadas (tabuada), como $6 \times 4,2 \times 3$, o que faz com que o jogador possa ser rápido em direcionar a sua nave e até acelerar quando tem segurança de sua resposta. A atenção neste momento é tanto mental quanto sensorial, pois exige foco nos processos mentais da resolução do cálculo e ainda necessita de visão e coordenação dos movimentos com o mouse, para direcionar a nave na direção correta.

Quanto aos aspectos de memória dos estudantes, na interação com os jogos Space Race e Batalha Matemática, ficou evidente que fazer cálculos mentais utilizando as operações básicas, bem como fazer estimativas, caracteriza a necessidade do armazenamento de fatos numéricos na memória como função necessária para o bom desempenho em Matemática. A automatização dos algoritmos faz com que sejam dadas respostas rápidas, como pode ser percebido em relação à memorização da tabuada: a resposta para $5 \times 3$ será dada muito mais rapidamente do que para $5 \times 12$, pois, comumente, memoriza-se a multiplicação por fatores entre 0 e 10 .

Nas atividades desenvolvidas, observaram-se aspectos de memória de trabalho (a memória operacional que serve para organizar a realidade percebida pelo cérebro) e de memória permanente (a responsável por armazenar todo o conhecimento de uma pessoa). A memória de trabalho é considerada um acesso rápido às memórias preexistentes do indivíduo, o sistema gerenciador central responsável por manter a informação viva pelo tempo suficiente para que seja processada (IZQUIERDO, 2010, p. 27). Foi possível verificar a memória de trabalho em ação, quase que ininterrup- 
tamente, quando os estudantes faziam os cálculos e as associações numéricas nas expressões, ao mesmo tempo em que precisavam também de acesso aos aprendizados já armazenados na memória permanente para dar fluidez ao jogo. É em razão disso que a memória de trabalho assume o papel gerenciador: ao receber qualquer tipo de informação, num sistema coordenado com outras conexões mnemônicas, estabelecem-se possíveis relações da experiência atual com outras semelhantes, das quais possa haver registro: o aprendizado (IZQUIERDO, 2010, p. 27-28).

A memória de trabalho depende da atividade elétrica de neurônios do córtex pré-frontal, que são ativados em resposta às experiências de cada momento, por exemplo, a "leitura" dos numerais e das operações presentes no cálculo. Depois de processada, a informação será comparada com outras informações que possam estar associadas ou que já estejam guardadas no cérebro (memória permanente), como o algoritmo da subtração, por exemplo (IZQUIERDO, 2010, p. 27).

Diante disso, observou-se, pela fala dos estudantes, que, embora com as características próprias de cada uma delas, as memórias de trabalho e permanente agem interconectadas para o desenvolvimento das atividades de cálculo presentes no jogo. Consequentemente, foi possível constatar três componentes do mecanismo de processamento mental feito pelos estudantes: 1) evocação da memória permanente para identificação do símbolo operacional, por exemplo, o algarismo 4; 2) evocação da memória permanente dos fatos aritméticos básicos, por exemplo, a tabuada ( 4 x 7 = 28); e 3) execução do procedimento de cálculo e de ações próprias do jogo, fazendo uso da memória de trabalho.

Essa é uma forma de explicar o funcionamento dos circuitos cerebrais envolvidos não só no processamento numérico, mas também no processamento de cálculos matemáticos envolvidos nos jogos digitais.

\section{Considerações finais}

Neste artigo, buscou-se esclarecer e definir atenção e memória, funções que estão na base da construção da aprendizagem, sendo a primeira responsável pela aquisição de novos conhecimentos e a segunda, pela retenção dos conhecimentos aprendidos.

Necessitamos da atenção para direcionar o foco ao que deve ser aprendido e utilizamos a memória para realizar tarefas a todo o momento, inclusive as que exijam raciocínio, como operações matemáticas, por exemplo. Consequentemente, 
podemos concluir que, juntas, a atenção e a memória alicerçam a aprendizagem, o que dá sentindo a tudo o que somos e fazemos.

Ao incorporar jogos digitais como ferramentas facilitadoras nos processos de ensinar e aprender, o professor pode contar com uma incrível variedade de possibilidades para desenvolver aulas dinâmicas e divertidas no contexto das tecnologias para as quais os estudantes, nativos digitais, mostram-se muito motivados.

$\mathrm{O}$ que de fato contribui para a aprendizagem dos estudantes por meio de jogos digitais é que, cada vez que uma informação é recuperada da memória, as redes neuronais específicas são ativadas, se fortalecem e ampliam conexões com outros neurônios por meio das sinapses, expandindo o conhecimento. Por exemplo, quanto mais pratica mentalmente as operações básicas da matemática, mais rápido o estudante poderá dar a resposta e maior a chance de que esteja correta.

Enfim, constata-se que os jogos digitais on-line beneficiam os estudantes na aprendizagem dos conceitos básicos da Matemática e desenvolvem as funções cognitivas de atenção e memória, imprescindíveis para a disciplina.

\section{The online digital game and the cognitive functions of attention and memory in Mathematics: a study in neurosciences}

\section{Abstract}

This article aims to present an educational product related to the research developed in the Postgraduate Program Professional Postgraduate Program in Education - UFFS Campus Erechim, this is the online digital game: Space Race and Mathematical Battle, which offers strategies for the development of human cognitive functions. From the profile of the native digital students, it presents the game as an innovative perspective to the processes of teaching and learning. We highlight a brief review of studies related to the cognitive functions of attention and memory associated to the use of Digital Information and Communication Technologies in the Neuroscience perspective. The results point out that the student maintains the sensorial / mental attention focused on the activity when interacting with the game, as well as, makes use of working memory, and processes of evocation and permanent memory consolidation, consequently, this and other digital games, can be considered important allies to the mathematical learning.

Keywords: Digital games. Learning. Attention. Memory. Mathematics. 


\section{Nota}

1 Expressão que denomina os jovens que nasceram nas últimas décadas e representam as primeiras gerações que viverão toda a sua vida cercados de ferramentas digitais (PRENSKY, 2001, p. 1).

\section{Referências}

BORBA, Marcelo de Carvalho; SILVA, Ricardo Scucuglia R.; GADANIDIS, George. Fases das tecnologias digitais em educação matemática: sala de aula e internet em movimento. Belo Horizonte: Autêntica, 2014.

COSENZA, Ramon M.; GUERRA, Leonor B. Neurociência e educação: como o cérebro aprende. Porto Alegre: Artmed, 2011.

GOLEMAN, Daniel. Foco: a atenção e seu papel fundamental para o sucesso. Rio de Janeiro: Objetiva, 2014.

HERCULANO-HOUZEL, Suzana. Neurociências do aprendizado. São Bernardo do Campo: Nitta's Digital Vídeo, 2009. 1 DVD. (30 min).

IZQUIERDO, Iván. A arte de esquecer: cérebro e memória. 2. ed. Rio de Janeiro: Vieira \& Lent, 2010.

IZQUIERDO, Iván. Memória. 2. ed. Porto Alegre: Artmed, 2001.

IZQUIERDO, Iván. Memórias. Estudos Avançados, v. 3, n. 6, p. 89-112, ago. 1989.

LENT, Roberto. Cem bilhões de neurônios: conceitos fundamentais de neurociência. 2. ed. São Paulo: Atheneu, 2010.

POZO, Juan Ignacio. Aprendizes e mestres: a nova cultura da aprendizagem. Porto Alegre: Artmed, 2002.

PRENSKY, Marc. Aprendizagem baseada em jogos digitais. Tradução de Eric Yamagute. São Paulo: Editora Senac, 2012.

PRENSKY, Marc. Digital Natives, Digital Immigrants. MCB University Press, 2001. Disponível em: http://www.marcprensky.com/writing/Prensky\%20-\%20Digital\%20Natives,\%20Digital\%20 Immigrants\%20-\%20Part1.pdf. Acesso em: 27 maio 2017.

SANTOS, Wilk O.; SILVA JUNIOR, Clovis G. Uso de jogos no ensino da Matemática: uma análise entre os jogos tradicionais e os jogos digitais, baseada em pesquisa e mapeamento dos materiais encontrados na Web. 2014. Disponível em: http://www.comunidadesvirtuais.pro.br/seminario-jogos/2014/trabalhos-aprovados/. Acesso em: 20 set. 2016.

SCHEFFER, Nilce Fátima. Tecnologias digitais e representação matemática de movimentos corporais. Curitiba: Appris, 2017.

SILVA, Sindia Liliane Demartini; SCHEFFER, Nilce Fátima. Os jogos digitais online na educação matemática: apontamentos da neurociência cognitiva. In: ENCONTRO NACIONAL DE EDUCAÇÃO MATEMÁTICA, 12, 2016, São Paulo. Anais... São Paulo, 2016. Disponível em: www. sbembrasil.org.br/enem2016/anais/pdf/6684_2995_ID.pdf. Acesso em: 5 set. 2017.

TAROUCO, Liane Margarida R. et al. Jogos educacionais. Porto Alegre: Cinted/Ufrgs, 2014. Disponível em: http://www.cinted.ufrgs.br/ciclo3/af/30-jogoseducacionais.pdf. Acesso em: 10 set. 2015. 